Review

\title{
Tri-n-Butylborane/WaterComplex-Mediated Copolymerization of Methyl Methacrylate with Proteinaceous Materials and Proteins: A Review
}

\section{Seiichiro Fujisawa $^{1, *}$ and Yoshinori Kadoma ${ }^{2}$}

1 Meikai University School of Dentistry, Sakado, Saitama 350-0283, Japan

2 Institute of Biomaterials and Bioengineering, Tokyo Medical and Dental University, Kanda-surugadai, Chiyoda-ku, Tokyo 101-0062, Japan; E-Mail: y-kadoma.fm@tmd.ac.jp

* Author to whom correspondence should be addressed; E-Mail: fujisawa33@nifty.com; Tel.: +81-049-279-2778; Fax: +81-492-876-657.

Received: 23 August 2010; in revised form: 8 October 2010 / Accepted: 5 November 2010 / Published: 15 November 2010

\begin{abstract}
Previous studies of tri- $n$-butylborane-initiated graft copolymerization of methyl methacrylates with hydrated proteinous materials and proteins have focused on the number of grafted-poly (MMA) branches as well as the percent graft and graft efficiency. The number of branches in silk fibroin is 1.3 , whereas the number in collagen, gelatin, ovalbumin and wool are 0.1, 0.04, 0.02 and 0.03, respectively. The number of grafted-PMMA branches in synthetic poly-L-peptides is approximately 10-fold less than that in gelatin, and decline, in the order poly-Ala $>$ poly-Ser $>$ poly-Pro $>$ poly-Glu $>$ poly-Lys. By contrast, poly-Gly, poly-Tyr and poly-Leu have no branches. The co-catalytic effect (the ratio of the number of polymer formed relative to that of control) of amino acids on tri-n-butylborane-initiated polymerization of MMA in the presence of water has been linearly correlated with their

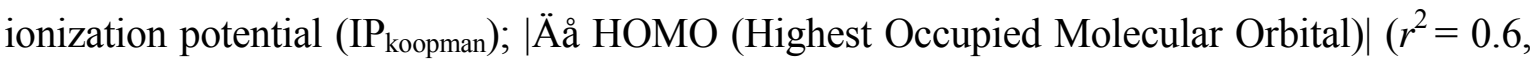
outliers: Cys and His); Äå HOMO = [åHOMO semiempirical AM1 method. Also, a significant exponential relationship between the number of branches of poly-L-polypeptides and the Äå HOMO of the corresponding amino acids has been observed $\left(r^{2}=0.9\right)$. A possible grafting site of protein (polypeptide) is discussed.
\end{abstract}

Keywords: tri- $n$-butylborane; graft copolymerization; MMA; water; poly-L-peptides; collagen; gelatin; silk fibroin 


\section{Introduction}

Bonding of restorative monomers is an attractive technique for improving the surface characteristics of teeth and bone after treatment of caries in dentistry or as bone cement in orthopedics. Rao et al. [1] and Brauer and Termini [2] previously reported that collagen could be modified using acrylates, methacrylates and vinyl monomers containing a variety of functional groups using ceric ions as initiators. Ceric ions react with hydroxyl groups in the side chains of hydroxyproline, hydroxylysine, serine (Ser) and threonine (Thr) residues of collagen [2]:

$$
\mathrm{Ce}^{\mathrm{IV}}+\mathrm{RCH}_{2} \mathrm{OH} \rightleftarrows \text { ceric alcohol complex } \rightarrow \mathrm{Ce}^{\mathrm{III}}+\mathrm{H}^{+}+\mathrm{RC} \cdot \mathrm{HOH}
$$

The free radical formed on the carbon atom attached to the hydroxyl group of the polymeric backbone acts as an initiator for the polymerization of the graft side chain. Collagen may be grafted by monomers with substituents such as hydroxyl, cyano-, trifluoroethyl or glycidyl groups onto dentin and bones. However, clinical applications of this system to dental materials have not yet been reported, possibly because of the poor practical advantage of this system.

Masuhara [3] has reported that grafting to collagen and other proteinaceous materials could be accomplished through copolymerization of methyl methacrylate with tri- $n$-butylborane initiators. Polymer formation by methyl methacrylate is initiated on the physiological moist surface of dentin using this polymerization initiator. The cured monomer layer may act as a barrier that temporarily shortens and limits the cytotoxic effect of monomers on the pulp [4,5]. Bonding to dentin by the tri- $n$-butylborane-initiated resin is enhanced by the presence of moisture and the bonding strength is retained fairly well after water immersion. Commercial restoratives containing borane initiators have become available in dentistry [4]. Bonding exists only with dentin collagen, but not with tooth enamel. Therefore, certain pretreatment processes of the cavity with dentin and enamel have been employed for the borane-initiated commercial products.

Polymerization of MMA initiated, by in part, oxidized-tri- $n$-butylborane, is accelerated in the presence of hydrated collagen powder and decalcified dentin slices treated with ferric chloride [6]. An adhesive borane-system with methyl methacrylates containing circa 10 wt.\% borane initiator and 5 wt.\% 4-methacryloyloxyethyl trimellitate anhydride (4-META) has been further developed by Nakabayashi et al. [7] and is now available for dental application.

There have been many reports of tri- $n$-butylborane-initiated graft copolymerization of MMA onto proteins [8-13]; for example, the grafting of methyl methacrylate (MMA) onto collagen [8], chitin [9], cotton [10], silk fiber [11], blood [12], and hemoglobin [13]. These applications have been investigated over the course of the last four decades. Grafting of MMA with collagen proceeds by a radical mechanism via a complex of tri- $n$-butylborane and hydrated collagen, and no grafting of MMA by tri- $n$-butylborane is observed in the absence of water or in the usual organic solvents such as $n$-hexane, tetrahydrofuran and cyclohexanone [8]. However, attempts to clarify the mechanism of grafting have so far proved unsuccessful. In many reports, the grafting activity to proteins has been evaluated by the percentage of grafting, but not by the number of grafted-poly (MMA) branches. Also, the backbone polymer, particularly in the case of dentin collagen, has not been appropriately addressed. Furthermore, previous studies have focused on the reaction mechanism of tri- $n$-butylborane, which was identified at an early stage of investigations of organic borane chemistry [14-16]. 
Borane derivatives are now becoming key reagents in radical chemistry, and have been used to develop an attractive new procedure for the reduction of radicals with alcohol and water [17]. To clarify the mechanism of grafting of trialkylborane-initiated MMA resins with protein materials, we review here the results of our previous studies [18-20] on the basis of published materials and current knowledge.

\section{Tri-n-Butylborane as a Polymerization Initiator}

Welch [15] has reported the polymerization of vinyl monomers by alkylboranes in the presence of oxygen or electron donors; polymerization proceeds via a free-radical mechanism. Also, Kojima et al. [21,22] have extensively examined the copolymerization of vinyl monomers by tri-n-butylborane. For example, the alkylborane-initiated polymerization of vinyl chloride was found to be accelerated by electron-donating solvents such as ether and pyridine, and it was assumed that alkylborane formed a complex with these donors [21]. The same authors also reported the polymerization of MMA initiated by tri-n-butylborane-metal acetylacetonate in DMSO or toluene, and showed that the activation energy $\left(E_{a}\right)$ of polymerization of MMA by the tri- $n$-butylboraneacetylacetonate complex in dioxane was $5.5 \mathrm{kcal} / \mathrm{mol}$, whereas that for the polymerization of acrylonitrile by tri- $n$-butylborane in tetrahydrofuran was $3.8 \mathrm{kcal} / \mathrm{mol}$. For comparison, the $\mathrm{E}_{\mathrm{a}}$ for benzoyl peroxide (BPO) and azobis-isobutyronitrile (AIBN) has been reported to be $26-33 \mathrm{kcal} / \mathrm{mol}$, whereas that of a BPO-tertiary amine redox system is $15-26 \mathrm{kcal} / \mathrm{mol}$ [22]. In contrast, the $\mathrm{E}_{\mathrm{a}}$ of tri-n-butylborane is $4 \mathrm{kcal} / \mathrm{mol}$ [15]. Tri- $n$-butylborane shows a considerably small $\mathrm{E}_{\mathrm{a}}$. Complexes of tributylborane with ammonia or primary and secondary amines are more stable in air and are easily activated by the action of acid chlorides and $p$-toluensulfonyl chloride [23].

In 1961, Mirviss [14,16] proposed a possible mechanism for the air oxidation of trialkylboranes (Scheme 1, a radical mechanism) [14], which was revised in 1967 (Scheme 2, an ionic radical mechanism) [16]. More recently, Penaud et al. [17] have reported that homolytic substitution at borane moieties does not proceed with carbon-centered radicals, and that many different types of heteroatom-centered radicals (e.g., alkoxyl radicals) react efficiently with organoboranes. The first step of homolytic substitution is the formation of a Lewis acid-base complex between the borane and the radical. This complex can then undergo $\beta$-fragmentation, producing the alkyl radical.

Scheme 1. Air oxidation of trialkylborane.

\section{JACS}
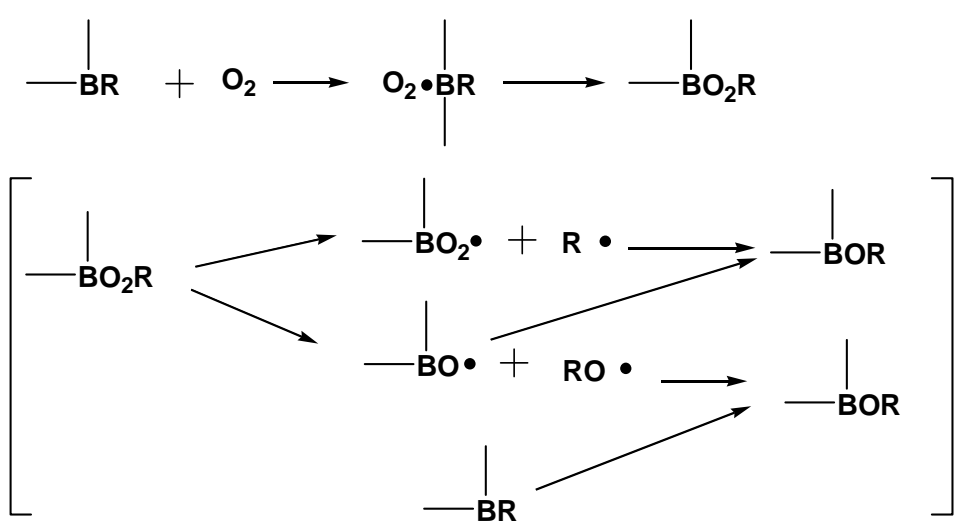
Scheme 2. Mechanism of the oxidation of trialkylborane.

1967 JOC

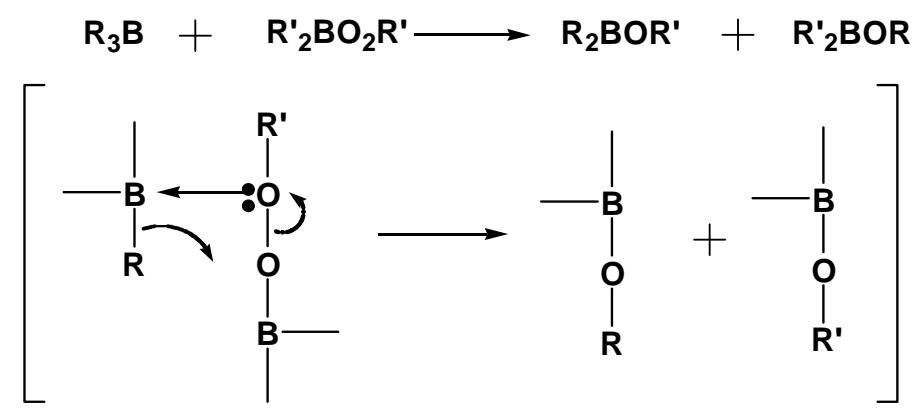

The use of triethylborane and other organoboranes as chain-transfer reagents has been reviewed previously [17]. In these processes, the organoborane acts as an initiator and as a reagent that propagates the chain. Although a number of borate esters have been investigated as catalysts for the polymerization of methyl methacrylates [21,22], little is known about the factors affecting the acid-base complex in the presence of a small amount of water.

\section{Copolymerization with Proteinaceous Materials and Proteins}

\subsection{Proteinaceous Materials}

Amino acids and synthetic poly-L-homopolypeptides can be used to model proteins. First, the co-catalytic effect of amino acids will be discussed.

\subsubsection{Amino Acids}

Kojima et al. [24] have investigated the co-catalytic effects (conversion) of amino acid esters in the polymerization of MMA by tri- $n$-butylborane. Polymerizations of MMA by tri- $n$-butylborane are carried out in dimethylsulfoxide (DMSO) and/or toluene in the presence of methyl esters of amino acids. The co-catalytic effects of amino acid esters decline in the order: methyl tyrosinate $>$ dimethyl glutamate $>$ dimethyl aspartate $>>$ methyl phenylalaninate $>$ methyl serinate $>$ methyl glycinate. Tyrosinate, glutamate and aspartate promote, whereas phenylalaninate, serinate and glycinate retard the polymerization. The rate of polymerization in a mixture of DMSO and toluene is proportional to the square root of the concentration of the initiator system, to the monomer concentration, and to the concentration of DMSO in the solvent. The above authors concluded that the polymerization of MMA by tri- $n$-butylborane proceeds via a radical mechanism, and also that the amino acid esters act as electron donors. It has been reported that 4-methoxy-6-tert-butylphenol (BHA), a most effective inhibitor of a number of common phenolic antioxidants, exhibits no inhibitory effect on auto-oxidation of tri-sec-butylborane in benzene, whereas among phenolic antioxidants, galvinoxyl alone exhibits an inhibitory effect in this setting; there is a very slow interaction between butylborane and galvinoxyl over a period of days [25]. Methyl tyrosinate seems to show no inhibitory effect in the tri-n-butylborane reaction system, even though it is a phenolic antioxidant. 
Table 1. Co-catalytic effects of L-amino acid on polymerizations of methyl methacrylate by tri-n-butylborane in the presence of water.

\begin{tabular}{|c|c|c|c|c|c|c|}
\hline & $\begin{array}{l}\text { Wt.of total } \\
\text { polymer } \\
\mathrm{g}\end{array}$ & $\begin{array}{l}\text { Mol. wt. } \\
\times 10^{-4}\end{array}$ & $\begin{array}{l}\text { No. of polymer } \\
\text { formed } \\
\times 10^{6}(\mathrm{~mol}) \\
\end{array}$ & $\begin{array}{l}{ }^{*} \text { Ratio of no. of polymer } \\
\text { formed to that of control }\end{array}$ & $\begin{array}{c}\text { \# } \ddot{A ̈ a ̊}_{\text {номо }} \\
\mathrm{eV}\end{array}$ & $\begin{array}{c}\text { Ionization potential } \\
\text { (IP), }\left|\ddot{A ̈}_{\text {HOMO }}\right| \\
\mathrm{eV}\end{array}$ \\
\hline $\mathrm{Con}^{\text {a) }}$ & 0.523 & 6.2 & 8.53 & 1 & - & - \\
\hline Try & 0.548 & 5.8 & 9.5 & 1.2 & -0.2087 & 0.2087 \\
\hline Phe & 0.551 & 5.3 & 10.4 & 1.3 & 0.0694 & 0.0694 \\
\hline His & 0.555 & 5.1 & 10.9 & 1.3 & -0.7708 & 0.7708 \\
\hline Met & 0.509 & 5.0 & 10.2 & 1.2 & -0.0860 & 0.0860 \\
\hline Val & 0.585 & 5.7 & 10.3 & 1.2 & 0.0057 & 0.0057 \\
\hline Ser & 0.627 & 5.0 & 12.5 & 1.5 & 0.1590 & 0.1590 \\
\hline Tyr & 0.539 & 6.6 & 8.2 & 1.0 & -0.1161 & 0.1161 \\
\hline Glu & 0.533 & 6.6 & 8.1 & 1.0 & -0.0730 & 0.0730 \\
\hline Ala & 0.58 & 5.1 & 11.3 & 1.3 & 0.1841 & 0.1841 \\
\hline Thr & 0.444 & 4.9 & 9.0 & 1.1 & -0.0571 & 0.0571 \\
\hline Lys & 0.615 & 4.7 & 13.1 & 1.6 & -0.3850 & 0.3850 \\
\hline $\mathrm{Con}^{\mathrm{b})}$ & 0.422 & 12.0 & 3.5 & 1 & & \\
\hline Leu & 0.451 & 9.5 & 4.7 & 1.3 & -0.0568 & 0.0568 \\
\hline Arg & 0.41 & 8.3 & 4.9 & 1.4 & -0.3164 & 0.3164 \\
\hline Pro & 0.462 & 10.4 & 4.4 & 1.2 & 0.0102 & 0.0102 \\
\hline Asp & 0.511 & 10.8 & 4.7 & 1.3 & 0.1711 & 0.1711 \\
\hline Gly & 0.535 & 12.7 & 4.2 & 1.2 & 0.0143 & 0.0143 \\
\hline Cys & 0.401 & 10.9 & 3.7 & 1.1 & -0.7233 & 0.7233 \\
\hline
\end{tabular}

Previously, we have investigated the co-catalytic effect of amino acids on tri- $n$-butylborane-initiated MMA polymerization in the presence of water [19]. Briefly, the amino acids employed $\left(10^{-4}\right.$ mol $)$ were dissolved in $10 \mathrm{~mL}$ of water in conical flasks, and then $5 \mathrm{~mL}$ of methyl methacrylate and $0.1 \mathrm{~mL}$ of tri-n-butylborane initiator were added. After a reaction time of one hour with stirring, at $37^{\circ} \mathrm{C}$, the polymerized monomers were precipitated with methanol and unpolymerized monomers, and amino acids were filtered off. The reaction products were then dried under reduced pressure and weighed. The molecular weight of the amino acid-PMMA product was determined by high-speed membrane osmometry, and the results are shown in Table 1. Experiment 1 was a Grignard reaction involving tri- $n$-butylborane prepared from borane trifluride etherate and $n$-butyl bromide [8], and Experiment 2 involved a commercial product (Table 1). The co-catalytic effect was evaluated in terms of the ratio of the number of polymers formed relative to that of the control. With regard to the control, the ratio declined in the order: Lys-HCl (hydrochloride) (1.6) > Ser (1.5) > Arg- $\mathrm{HCl}(1.4)>\mathrm{His}-\mathrm{HCl}$, Phe, Leu, Ala (1.3) > Met, Try, Val, Gly (1.2) > Thr, Cys (1.1) > Tyr, Glu, control (1.0). The amino acids, Lys, Arg and Ser, having a side chain with a functional group, exhibited the highest co-catalytic effect. Also, basic amino acids (Lys and Arg) exhibited a greater co-catalytic effect than that of acidic (Glu) or neutral (Tyr, Cys, Thr) amino acids. 


\subsection{Synthetic L-Polypeptides}

Although periodic polypeptides (homopolypeptides) do not exist in nature, knowledge of their structure can contribute to an understanding of the properties of proteins. The -CO-NH-C- main chain is common to all polypeptides and proteins. Also, the different side chains likely influence their contribution properties. Ten homopolypeptides: poly-Gly, poly-L-Ala, poly-DL-Ala, poly-L-Ser, poly-L-Leu, Poly-L-Pro, polyl-L-Lys, poly-L-Tyr, poly-L-Glu and poly-L-gamma-benzyl-glutamate, are outlined below [18,20]. Suspension polymerization $(10 \mathrm{ml}$ MMA, $0.15 \mathrm{~mL}$ initiator, $1 \mathrm{~mL}$ water, $0.022-0.055 \mathrm{~g}$ polypeptide, at $37{ }^{\circ} \mathrm{C}$ for $1 \mathrm{~h}$ ) was carried out in a conical flask with a stopper. The polymerization product obtained was washed thoroughly with acetone, dried in vacuo, and then weighed. Samples of polypeptide-MMA-grafted copolymer were treated with $2 \mathrm{~mL}$ of glacial acetic acid and $4 \mathrm{~mL}$ of $6 \mathrm{~N}$ hydrochloric acid at $100-110{ }^{\circ} \mathrm{C}$ for nine hours. The precipitate was then filtered, washed with water and methanol, and then dissolved in acetone, precipitated with methanol, dried in vacuo, and weighed. The molecular weight of separated polymers was determined in benzene at $30^{\circ} \mathrm{C}$. The infrared spectra of grafted PMMA were identical to that of the original PMMA. (Note: To prevent the hydrolysis of MMA with methacrylic acid, using a glacial acetic acid/HCl solution, methylation of PMMA branches was treated with diazomethane.)

Molecular weight determination of separated polymers: The intrinsic viscosity of the PMMA separated by treatment with glacial acetic acid/ $\mathrm{HCl}$ was determined in benzene at $30{ }^{\circ} \mathrm{C}$. The number-average molecular weight was calculated using the Equation 2 [18]:

$$
[c ̧]=8.69 \times 10^{-5} \mathrm{Mn}^{0.76}
$$

Characterization of the graft copolymerization was evaluated using the following Equations:

[Total conversion of monomer $(\%)$

$=[$ wt. of total polymer formed $] \times 100 /[$ wt. of monomer employed $]$

Percentage graft $=[$ wt. of graft branches $] \times 100 /[$ wt. of substrate polymer]

Graft efficiency $(\%)=$

[wt. of graft branches] $\times 100 /[$ wt. of total polymer formed]

The number of grafted-PMMA branches (mole/g-backbone polymer) $=$

[wt. of grafted-PMMA branches] $\times 100 /[$ wt. of grafted PMMA]

The results are shown in Table 2. No increase in the percentage graft was observed for poly-Gly, poly-L-Leu, poly-L-Tyr and poly-L- $\gamma$-benzyl glutamate. By contrast, the increase in the percentage graft is shown for poly-L-Ala, poly-L-Ser, poly-L-Pro, poly-L-Lys and poly-L-Glu; whereas the number of grafted-PMMA branches declined in the order: poly-L-Ala $>$ poly-L-Ser $>$ poly-DL-Ala $>$ poly-L-Pro > poly-L-Glu > poly-L-Lys.

The discrepancy between the two poly-alanines may be due to the type of helix; i.e., steric hindrance of the side chain between types L and D. The percentage graft for poly-L-tyrosine was zero, possibly due to its radical inhibition of the phenolic $\mathrm{O}-\mathrm{H}$ group. No grafting was also observed for poly-L-Leu and poly-L- $\gamma$-benzyl-glutamate. The weight of MMA-homopolymer formed, the molecular 
weight, and the number of polymers formed for the polypeptides as a whole were (1.1-1.3) $\mathrm{g}$, $(1.1-1.2) \times 10^{5}$ and $(10-11) \times 10^{-6}$ mol, respectively.

Table 2. Tri- $n$-butylborane-initiated graft copolymerization of methyl methacrylate with hydrated synthetic poly-L-peptides.

\begin{tabular}{|c|c|c|c|c|c|}
\hline & Percent graftt (\%) & $\begin{array}{l}\text { Mol. wt. of } \\
\text { grafted-PMMA }\end{array}$ & *No.branches & *No. branches & $\begin{array}{l}\Delta \varepsilon_{\mathrm{HOMO}} \text { of corresponding } \\
\text { amino acid }^{\mathrm{a}}\end{array}$ \\
\hline Polypeptide (pp) & $(\%)$ & $\times 10^{-5}$ & $(\mathrm{~mole} / \mathrm{g}-\mathrm{pp}) \times 10^{6}$ & $(\mathrm{~mole} / \mathrm{mole}-\mathrm{pp}) \times 10^{3}$ & $\mathrm{eV}$ \\
\hline Poly glycine & 0 & _ & 0 & 0 & 0.014 \\
\hline Poly-L-alanine & $86.1 \pm 9.7$ & $6.2 \pm 0.2$ & $1.4 \pm 0.1$ & 5.9 & 0.184 \\
\hline Poly-DL-alanine & 79 & 19.4 & 0.4 & 1.2 & _ \\
\hline Poly-L-leucine & 0 & _- & 0 & 0 & -0.057 \\
\hline Poly-L-serine & $108.2 \pm 43$ & $13.5 \pm 4.8$ & $0.8 \pm 0.3$ & 4.0 & 0.159 \\
\hline Poly-L-tyrosine & 0 & _ & 0 & 0 & -0.116 \\
\hline Poly-L-lysine $e^{\text {b) }}$ & $18.0 \pm 4.2$ & $12.9 \pm 0.1$ & $0.1 \pm 0.1$ & 0.3 & -0.385 \\
\hline Poly-L-proline ${ }^{\text {b) }}$ & $49.3 \pm 6.7$ & $23.2 \pm 0.2$ & $0.2 \pm 0.0$ & 2.0 & 0.012 \\
\hline Poly-L-glutamic acid & $25.1 \pm 2.6$ & $12.8 \pm 0.3$ & $0.2 \pm 0.0$ & 0.8 & -0.073 \\
\hline \multicolumn{6}{|l|}{ Poly-L- $\tilde{\gamma-b e n z y l}$} \\
\hline glutamate & 0 & & 0 & 0 & \\
\hline
\end{tabular}

${ }^{a}$ taken from the literature [29], ${ }^{*}$ Number of grafted-PMMA branches ${ }^{b}$ treated with $2 \%$ formalin for $10 \mathrm{~min}$. The values are the mean \pm SD for three independent experiments. The experimental procedure is described in the text.

Currently, computational chemistry has being applied for analyzing the transition structures for the hydroboration of alkenes by borane compounds at the semi-empirical MO calculation level and DFT levels [26-28]. It has been reported previously that the relative rates of hydroboration of alkenes are well correlated with their semi-empirical MNDO-calculated HOMO energy level. The higher the HOMO energy of alkenes, the faster the reaction proceeds. This can be accounted for by the enhanced interaction between the HOMO of alkenes and the LUMO of boranes when they are brought together. Formation of the B-C bond occurs predominantly at the position where the atom orbital coefficient in the alkene HOMO is largest [26,27]. To explain the present co-catalytic effect of amino acids and the graft copolymerization with polypeptides, the HOMO-LUMO interaction provides a deeper understanding of tri- $n$-butylborane-initiated polymerization and copolymerization chemistry. The HOMO energy of amino acids is derived from published data [29] (Table 1). Briefly, the initial configurations of amino acids are fully optimized with the semi-empirical AM1 method using MOPAC (FUJITSU MOPAC 2002). The $\Delta \varepsilon$ HOMO is determined using the following equation:

$$
\Delta \varepsilon \mathrm{HOMO}=\varepsilon \mathrm{HOMO}_{\text {aqua }}-\varepsilon \mathrm{HOMO}_{\text {vacuum }}
$$

As shown in Table 1, the basic amino acids, Arg, Lys and His, having a large minus $\Delta \varepsilon$ HOMO energy, show a large co-catalytic effect, due to their positively charged side chains. The HOMO energy is comparable with the ionization potential (IP) provided by Koopmans' theorem, $|\varepsilon H O M O|[30]$. The relationship between the co-catalytic effect (the ratio of the number of polymers formed relative to that of the control) and IP for amino acids has been examined. An acceptable correlation between the co-catalytic effect and IP was observed, with the exception of Cys and His. The equation is as follows: 


$$
\begin{gathered}
\text { Co-catalytic effect }=1.12( \pm 0.11)+1.11( \pm 0.26) \text { IP } \\
\left(\mathrm{n}=14, r^{2}=0.597, \mathrm{p}<0.01, \text { outlier: } \text { Cys, His }\right)
\end{gathered}
$$

The higher the IP of amino acids, the higher the co-catalytic effect.

Tri- $n$-butylborane-initiated polymerization of MMA in the presence of amino acids and water in air is controlled by the IP value of the amino acid. Cys with a thiol side chain and His with an imidazole side chain are outliers. It is well known that trialkylboranes react with thiols even at room temperature. Also, tri- $n$-alkylborane may form a strong complex with His due to its high IP value.

The HOMO in MMA is located on the $\beta$-carbon of the double bond, and can be determined by semi-empirical MO calculation PM3 [31]. Using this method, the HOMO of some polypeptides such as poly-L-Ala and poly-Gly has been calculated. HOMO of poly-L-Ala, with a relatively high percentage graft value, is located at the position of its terminal $\mathrm{NH}_{2}$. In contrast, $\mathrm{HOMO}$ of poly-Gly and that of poly-L-Leu, having a percentage graft value of zero, is located at the position of intramolecular NH (data not shown). Polypeptides with HOMO located in the intramolecular $\mathrm{NH}$ group may undergo graft copolymerization only with difficulty because of the steric hindrance of the polypeptide helix, particularly, for long bulky side-chain polypeptides. In this connection, the terminal $\mathrm{NH}_{2}$ of the end groups in polypeptides may be the most favorable grafting site when HOMO is located in this position. The regioselectivity of HOMO on polypeptides should be examined further.

Consideration of the interaction of HOMO of alkenes and LUMO of boranes [26,27] could be applied for study of polypeptides. The relationship between the number of grafted-PMMA branches of polypeptides and the $\Delta \varepsilon \mathrm{HOMO}$ of corresponding amino acids has been examined. A significantly exponential relationship between the two parameters was observed (Figure 1).

Figure 1. Relationship between the number of grafted-PMMA branches of poly-L-peptides and the $\Delta \varepsilon$ HOMO of the corresponding amino acids.

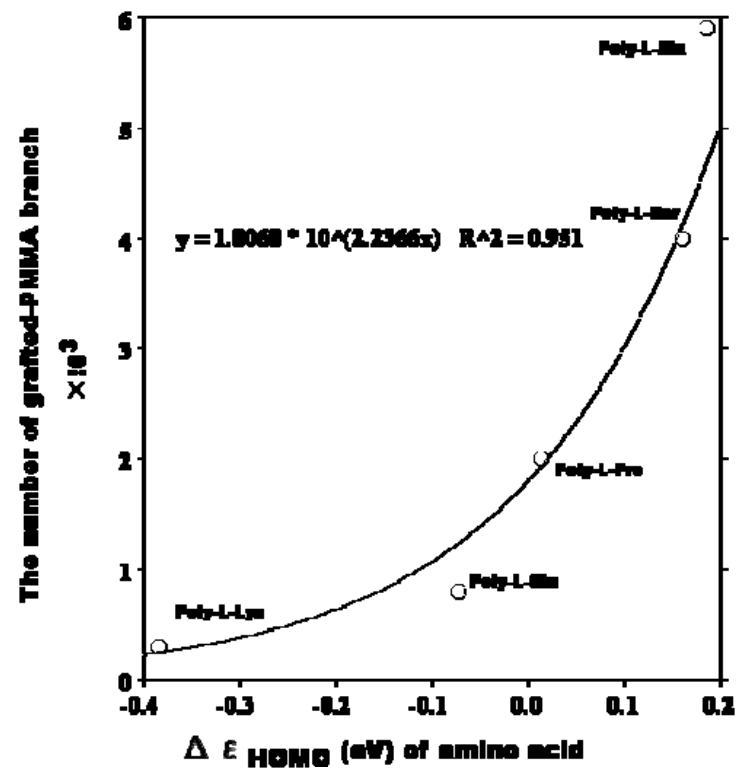

The higher the $\Delta \varepsilon$ HOMO becomes, the higher the number of grafted-PMMA branches. However, further studies of this graft mechanism at a higher level of calculation will be necessary. 
A small amount of water may play an important role in tri- $n$-butylborane-initiated copolymerization of MMA with proteins. The theoretical $a b$ initio calculation has proposed that a $\mathrm{O}-\mathrm{H}$ homolysis reaction in the trimethylborone/water complex is endothermic, and its $\mathrm{O}-\mathrm{H}$ homolysis reaction is much lower than that for pure water: the $\mathrm{O}-\mathrm{H}$ bond dissociation energy of water $(73 \mathrm{kcal} / \mathrm{mol})$ in the borane/water complex is much lower than that of water [28]. It has been proposed that the trimethylborane/water complex mediates methyl radical generation.

The co-catalytic effect of amino acids on the tri-n-butylborane-initiated polymerization of MMA in the presence of water is controlled by IP, suggesting that this system proceeds via a Lewis acid (tri-n-butylborane)/base (amine) complex, as shown in Scheme 3. The tri-n-butylborane/water complex-mediated polymerization system probably belongs to a cation radical polymerization of methyl methacrylate.

Scheme 3. Reactivity of carbon- and heteroatom-centered radicals with organoboranes [17].

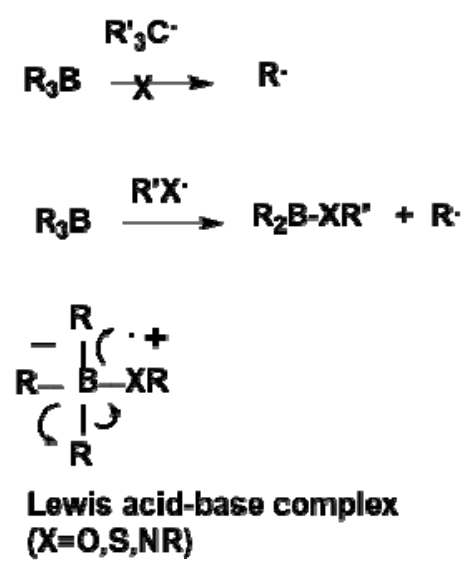

\subsection{Copolymerization with Proteins}

\subsubsection{Silk Fibroin}

The results of copolymerization with five types of proteins, rat-tail collagen, wool, gelatin, ovalbumin and silk fibroin, are shown in Table 3.

The percent graft and graft coefficiency for untreated proteins declines in the order: gelatin $>$ silk fibroin $>$ collagen $>$ ovalbumin $>$ wool. The statistically significant relationship between the percent graft and graft coefficiency is observed $\left(r^{2}=0.91\right)$. However, no significant relationship between the number branches (mole/mole-protein) and the percent graft or graft coefficiency is observed. The percent graft and graft coefficiency for silk fibroin are greater than those for collagen. The number of PMMA branches is $0.1,0.025,0.04,0.02$ and 1.3, respectively. Silk fibroin has a one-order greater number of grafting sites than rat-tail collagen. To clarify the good ability of silk fibroin to graft polymerization, it would be important to comprehensively delineate relationships between the chemical structure of proteins (backbone polymer) and grafting sites (No. of branches) or the molecular weight of grafted-PMMA branches. Recently, Cao and Wang [32] have reported a review of silk-based biomaterials. The structure of silk can be concisely described as follows: Silk fibroin is a giant molecule, of which about two thirds is a crystalline portion and about one third is an amorphous 
region. The crystalline portion contains repetitive amino acids (-Gly-Ala-Gly-Ala-Gly-Ser-) along its sequence, forming an antiparallel â-sheet, which is formed through hydrogen bonding with the adjacent peptide chain, thus accounting for the stability and mechanical properties of the fiber. The silk fibroins are characterized as natural block copolymers comprising hydrophobic blocks with short side-chain amino acids such as Gly and Ala, and hydrophilic blocks with larger side-chain amino acids, as well as charged amino acids. The two main distinct structures in silk fibroin are silk I and silk II. The structure of silk I contains random-coil and amorphous regions; it is a water-soluble structure. The silk II structural form of the silk fibroins has been characterized as an antiparallel â-sheet structure that is insoluble in several solvents including mild acid and alkali, and several chaotropes. In regenerated silk fibroins, the silk I structure can be easily converted to a â-sheet structure by chemical methods such as treatment with methanol. About $75-80 \%$ of silk comprises a Gly-Ala sequence, and is about 5\% Ser.

Table 3. Tri-n-butylborane-initiated graft copolymerization of methyl methacrylates with hydrated rat-tail collagen, wool, gelatin and silk fibroin.

\begin{tabular}{|c|c|c|c|c|c|c|}
\hline Protein & Percent graft & $\begin{array}{l}\text { Mol. wt. of } \\
\text { grafted-PMMA } \\
\text { branches }\end{array}$ & *No. branches & *No. branches & $\begin{array}{l}\text { Graft } \\
\text { efficiency }\end{array}$ & $\begin{array}{l}\text { Total } \\
\text { conversion of } \\
\text { monomer }\end{array}$ \\
\hline & $(\%)$ & $\times 10^{-5}$ & $\begin{array}{c}\text { (mole/g-protein) } \\
\times 10^{6}\end{array}$ & $(\text { mole/mole-protein })^{\mathrm{d})}$ & $(\%)$ & $(\%)$ \\
\hline Collagen & $75.7 \pm 6.7$ & $18.2 \pm 1.9$ & $0.4 \pm 0.1$ & 0.1 & $2.6 \pm 0.2$ & $16.8 \pm 2.7$ \\
\hline Collagen $^{\mathrm{a}}$ & $139.1 \pm 17.7$ & $20.1 \pm 2.1$ & $0.7 \pm 0.2$ & 0.2 & $2.5 \pm 0.1$ & \\
\hline Wool & 11.5 & 3.1 & 0.5 & 0.025 & 0.8 & 9.3 \\
\hline Gelatin & $130.8 \pm 35.9$ & $19.9 \pm 3.4$ & $0.7 \pm 0.3$ & 0.04 & $3.8 \pm 0.6$ & $19.6 \pm 1.8$ \\
\hline Ovalbumin & $44.6 \pm 7.6$ & $12.4 \pm 1.6$ & $0.3 \pm 0.0$ & 0.02 & $1.8 \pm 0.4$ & $15.9 \pm 2.1$ \\
\hline Silk fibroin & $85.5 \pm 21.4$ & $2.3 \pm 0.7$ & $3.6 \pm 0.2$ & 1.3 & $3.6 \pm 0.9$ & $11.8 \pm 0.1$ \\
\hline Silk fibroin $^{\mathrm{a}}$ ) & $25.7 \pm 5.9$ & $1.4 \pm 0.1$ & $1.8 \pm 0.5$ & 0.7 & $1.7 \pm 0.4$ & $10 \pm 1$ \\
\hline Silk fibroin $^{\text {b) }}$ & $26 \pm 3.6$ & $1.4 \pm 0.3$ & $1.8 \pm 0.3$ & 0.7 & & 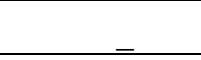 \\
\hline Silk fibroin $^{c)}$ & 249.4 & 6.4 & 3.9 & 1.4 & & \\
\hline
\end{tabular}

${ }^{\mathrm{a}}$ treated with acetic anhydride and pyridine $\left(1: 1\right.$, molar ratio) in benzene solution for $2 \mathrm{~h}$ at $60{ }^{\circ} \mathrm{C} ;{ }^{\mathrm{b}}$ treated with 2-tolylisocyanatein benzene solution for $2 \mathrm{~h}$ at $60{ }^{\circ} \mathrm{C}$; ${ }^{\mathrm{c}}$ treated with formic acid vapor for $72 \mathrm{~h}$; dapproximate values; * the number of grafted-PMMA branches; experimental condition (sample weight, $0.049 \mathrm{~g}-0.077 \mathrm{~g}$; MMA, $10 \mathrm{ml}$; tri- $n$-butylborane, $0.15 \mathrm{~mL} ; 37^{\circ} \mathrm{C}$ and for $1 \mathrm{~h}$ ). The weight and average molecular weight of MMA homopolymer are $0.84-1.44 \mathrm{~g}$ and $(1.1-1.2) \times 10^{-5}$, respectively. Values are the mean $\pm \mathrm{SD}$ for 2-5 independent experiments.

The average molecular weight of grafted-PMMA branches of silk fibroin is approximately $2 \times 10^{5}$, being one order less than that of collagen, gelatin and hydrophilic poly-L-peptides (Lys, Pro, Glut). In this system, the average molecular weight of the homopolymer is approximately $1.1 \times 10^{5}-1.2 \times 10^{5}$, indicating that the molecular weight of the grafted PMMA is similar to that of a homopolymer. This finding suggests that grafting of MMA onto silk fibroin probably occurs at the surface of the protein. 2-Tolylisocyanate and formic acid have chemically modified the functional groups of the amino acids in silk fibroin. The percentage grafting and the number of PMMA branches of the treated-silk fibroin 
are reduced to approximately one half of the corresponding value for the original silk fibroin, indicating that hydrophilic blocks with larger side-chain amino acids, particularly charged amino acids, may be involved in the grafting sites of silk fibroin. Interestingly, even when modifiers have masked silk fibroin, the graft copolymerization results in a lower percentage of grafting. It is assumed from this that hydrophobic blocks with short side-chain amino acids, such as Gly and Ala, may be involved in the graft copolymerization. Also, silk fibroin treated with formic acid vapor for $72 \mathrm{~h}$ shows a large percentage grafting of $249 \%$, being approximately 10 -fold greater than that of isocyanate- or acetic acetic anhydride-treated, or original, silk fibroin. Formic acid vapor induces swelling of the backbone polymers. However, the number of its PMMA branches is similar to that of the control.

Tsukada et al. [11] have examined the infrared spectrum of poly(MMA)-grafted silk fibers using tri- $n$-butylborane, and demonstrated overlapping absorption bands of silk fiber with a $\beta$-sheet structure and those of the grafted MMA polymer. Also, a grafted silk fiber with a graft yield of more than $140 \%$ was shown to be composed of two endothermic peaks at $321{ }^{\circ} \mathrm{C}$ and $396{ }^{\circ} \mathrm{C}$ on the DSC curve, attributable to the thermal decomposition of silk fiber and grafted poly-MMA chain, respectively. Also, Tsukada et al. [33] have examined MMA-grafted silk fibers obtained by using potassium persulfate (KPS) and tri-n-butylborane, which were evaluated in terms of the gel permeation chromatography (GPC) elution pattern of the poly-MMA chains. A bimodal molecular weight distribution, with a heavy and a light component on the grafted silk fiber, was observed. The average molecular weight of the heavy component ranged from 48.5 to $200 \mathrm{kDa}$ for poly-MMA copolymerized by the KPS reaction system, and from 336 to $816 \mathrm{kDa}$ for the poly-MMA copolymerized by the tri- $n$-butylborane reaction system. The light component had an average molecular weight lower than 1,000 $\mathrm{Da}$, being similar in all the samples examined. Scanning electron microscopy (SEM) demonstrated the presence of MMA oligomers formed on the fiber surface during grafting. Taken together with the finding of our previous study, it seems that the masked portion of silk fibroin treated with modifiers is probably compatible with hydrophilic blocks that include larger side-chain amino acids/charged amino acids. The grafted-PMMA branches on the hydrophilic block may be responsible for the high molecular weight. Interestingly, the average number of branches does not exceed two. Poly-L-Ala and poly-Gly have been used as a model polypeptide of silk fibroin because silk contains predominantly Ala and Gly residues. The graft copolymerization of MMA with polypeptides occurs for poly-L-Ala but not for poly-Gly. Also, the characterization of graft copolymerization with poly-L-Ala is likely similar to that of silk. However, the most favorable grafting sites on silk fibroin remain unclear because the number of grafted-PMMA branches is very small.

\subsubsection{Collagens}

Collagen One (Type I) is contained in skin, tendon, vasculature, ligaments, organs, bone (the main component) and teeth (dentin, cementum). The collagen content of dentin is about $20 \%$, and that of other components (mainly minerals) is about $80 \%$, comprising hydroxyapatite $\left(\mathrm{Ca}_{10}\left(\mathrm{PO}_{4}\right)_{6}(\mathrm{OH})_{2}\right)$ with some phosphate. The sequence of collagen often follows the pattern Gry-Pro-X or Gly-X-Hyp, where $\mathrm{X}$ may be any of various other amino acid residues. Pro or hydroxyPro constitutes about $1 / 6$ of the total sequence, Gly accounting for $1 / 3$ and Ala for about 1/10 [34]. Also, gelatin is an irreversibly 
hydrolyzed form of collagen, with a similar amino acid composition, being mainly Gly $21 \%$, Pro 12\%, hydroxyPro12\%, Glu 10\% and Ala 9\% [34].

As shown in Table 4, the number of grafted-PMMA branches of gelatin is approximately double that of rat-tail collagen, possibly due to the higher cross-linking in collagen than that in gelatin. Comparing collagen treated with acetic anhydride/pyridine modifiers with the original form, this treatment enhances the number of grafted-PMMA branches in collagen. Collagen comprises a polar region and an amorphous region, similar to silk fibroin. A highly basic block is present in the triple helix near the the carboxyl terminus [35]. Even if this block is masked by treatment with modifiers, the percentage grafting is not reduced, but conversely enhanced, possibly due to the modifier's swelling effect on collagens. The average molecular weight of the grafted-PMMA branches of collagen and gelatin is similar (approximately $20 \times 10^{5}$ ). That of ovalbumin is $12 \times 10^{5}$, being half that of collagen. Ovalbumin is a monomeric phosphoprotein with 385 amino acid residues. The N-terminal protein is acetylated and contains four cysteine and one cysteine residue [36]. Hydrophobic interactions and disulfide bond formation between ovalbumin molecules is involved in aggregation and surface gelatinization [37]. This structure of ovalbumin may be responsible for the relatively large molecular weight of the grafted-PMMA branches. By contrast, wool, a fiber protein, shows characteristics of graft copolymerization similar to those of silk fiber protein. Each of the amino acid residues is distributed almost equally [38].

On the other hand, the molecular weight of the homopolymer for all tested proteins (collagen, gelatin, silk fibroin, ovalbumin and wool) is similar, being $1.1 \times 10^{-5}-1.2 \times 10^{5}$. Also, that of the homopolymer derived from modifier-treated silk fibroin and collagen is $1.1 \times 10^{5}$. A great difference in average molecular weight between the grafted-PMMA and the homopolymer is observed for collagen, gelatin and hydrophilic polypeptides. The considerably high molecular weight of the grafted-PMMA branches of these backbone polymers may be associated with the so-called "gel effect", i.e., a markedly increased molecular weight and entanglements in the bulk [39]. Indeed, it has been found that grafted PMMA is in part converted to an insoluble form even after intensive acetone extraction, possibly due to the entanglements of resin polymer in the bulky hydrophilic backbone polymer. These results may be attributed to the heterogeneity of the system.

Graft copolymerization of MMA onto chrome-tanned pig skin has been reported to occur upon irradiation with ${ }^{60} \mathrm{Co}$-rays, and proof of grafting has been obtained through the detection of amino acid end groups in the isolated grafts by reaction with ninhydrin [40]. It is assumed that the N-terminal groups of amino acid ends are involved in radical reactions in biological systems. Gelatin has $\mathrm{NH}_{2}$-Lys as a predominant end group. Ser, Thr, Ala, Asp and Glu residues also occur [34]. Furthermore, the end group of collagen has been estimated from enzymatically hydrolyzed collagen products (polypeptides), Gly being the main terminal amino acid ( $\mathrm{NH}_{2}$-Gly-Pro----), with much smaller amounts of other amino acids (Ala, Glu, Aspa) [34]. The N-terminal groups of silk fibroin comprise 92\% Gly [41]. The terminal end groups of the amino acid residues of many proteins commonly comprise Gly. Our results suggest that any $\mathrm{NH}_{2}$-Gly in the end group of a protein may not be involved in grafting because of the zero percentage grafting of polyglycine. If Gly residues are mainly related to graft copolymerization, a large number of grafted-PMMA branches would be observed for the indicated proteins. N-terminal groups of amino acid residues, i.e., Ala, Ser and Asp with a high $\Delta \varepsilon$ HOMO may become grafting site candidates. However, further study of this issue may be necessary. 


\subsubsection{Effect of Initiator Concentration on Graft Copolymerization}

The percentage grafting, the molecular weight of grafted-PMMA branches, the number of grafted-PMMA branches, grafting efficiency (\%) and the total conversion of monomer (\%) with varying initiator concentration are shown in Table 4.

Table 4. Effect of the concentration of tri- $n$-butylborane on the graft copolymerization of MMA onto hydrated bovine dentin collagen.

\begin{tabular}{cccccc}
\hline Tri- $n$-butylborane & Percent graft & $\begin{array}{c}\text { Mol. wt. of grafted- } \\
\text { PMMA branch } \\
\times 10^{2} \text { mol/liter }\end{array}$ & $\begin{array}{c}\text { No. of grafted-PMMA } \\
\text { branch } \times 10^{6} \\
\text { mol/g-protein }\end{array}$ & $\begin{array}{c}\text { Graft } \\
\text { efficiency } \\
(\%)\end{array}$ & $\begin{array}{c}\text { Total conversion } \\
\text { of monomer } \\
(\%)\end{array}$ \\
\hline 3 & 9.7 & 8.5 & 0.1 & 3.0 & 4.3 \\
4 & 40.0 & 53.2 & 0.2 & 5.4 & 10.0 \\
11 & 49.5 & 38.9 & 0.1 & 3.5 & 18.6 \\
19 & 81.8 & 49.8 & 0.2 & 5.0 & 22.5 \\
25 & 71.9 & 40.0 & 0.2 & 3.8 & 25.0 \\
37 & 5.8 & 8.5 & 0.1 & 0.2 & 32.0 \\
47 & 0.8 & & & 0.03 & 34.7 \\
\hline
\end{tabular}

Collagen, $0.060 \mathrm{~g}$; MMA, $5 \mathrm{~mL}$; water, $0.3 \mathrm{~mL}$; at $37^{\circ} \mathrm{C}$ for $1 \mathrm{~h}$.

To optimize the reaction conditions for obtaining the maximum percentage grafting, the concentrations of initiator were varied. A significant parabolic relationship between the percentage grafting or the molecular weight of grafted PMMA branches and the square root of the initiator concentration $\left(\mathrm{C}^{1 / 2}\right)$ yielded equations 9 and 10:

$$
\begin{aligned}
& \text { Percentage grafting }=-91.1+79.4( \pm 22.3) \mathrm{C}^{1 / 2}-9.8( \pm 2.6) \mathrm{C} \\
&\left(\mathrm{n}=7, r^{2}=0.887, \mathrm{p}<0.05\right)
\end{aligned}
$$

Molecular weight of grafted PMMA $=-54.2+48.8( \pm 9.0) \mathrm{C}^{1 / 2}-6.1( \pm 1.1) \mathrm{C}$

$$
\left(\mathrm{n}=6, r^{2}=0.947, \mathrm{p}<0.01\right)
$$

There is an acceptable relationship for the percentage grafting versus the molecular weight of grafted PMMA $\left(r^{2}=9.45, \mathrm{p}<0.01\right)$.

Above $37 \mathrm{~mol}$, the percentage grafting and the grafting efficiency decrease markedly.

By contrast, the total conversion of monomer (\%) is linearly related to the square root of the initiator concentration, and expressed as the following equation:

$$
\begin{aligned}
& \text { Total conversion of monomer }(\%)=-2.3( \pm 2.0)+5.6( \pm 0.4) \mathrm{C}^{1 / 2} \\
& \qquad\left(\mathrm{n}=7, r^{2}=0.99, \mathrm{p}<0.01\right)
\end{aligned}
$$

Termination occurs in free radical polymerization by one of two mechanisms: coupling or disproportionation. Either mechanism involves a reaction between two growing chain ends. Comparing Equation 9 with Equation 11, the termination mechanisms of homopolymers in MMA solution and the growing PMMA radical in the backbone polymers apparently differ. The growing PMMA radical derived from cation radical polymerization mediated by the tri-n-butylborane/water complex (i.e., tri- $n$-butylborane as a Lewis acid) may be terminated by the terminal $\mathrm{N}$-amino acid residues end group 
of backbone polymers such as collagen and gelatin. This is also assumed from the considerably small value of $E_{a}$ for tri-n-butylborane (4 kcal/mol) [15]. It is well known that polymerization initiators with a small $E_{a}$ preferably undergo ionic polymerization in water. Since the number of grafted-PMMA branches of collagen is considerably small (0.1), graft copolymerization of MMA onto collagen by tri- $n$-butylborane might be a pseudo-graft copolymerization.

The effect of time (0-120 min) on graft copolymerization with bovine dentin collagen has been examined [bovine dentin collagen, $0.050 \mathrm{~g}$; MMA, $10 \mathrm{~mL}$; initiator, $0.15 \mathrm{~mL}$; water, $0.2 \mathrm{~mL} ; 37^{\circ} \mathrm{C}$ ] (data not shown). The percentage grafting increases with reaction time, the relationship being significantly linear $\left(r^{2}=0.99\right)$. The percent grafting continues to increase even after $120 \mathrm{~min}$. The tri- $n$-butylborane/water complex-initiated copolymerization starts without an induction period, and polymerization continues for a relatively long time.

\subsubsection{Copolymerization with Various Collagens}

Table 5 shows the graft copolymerization of MMA with various hydrated collagens.

The number of grafted-PMMA branches is comparably small, whereas the molecular weight of grafted-PMMA branches is very high. Premature collagen (calf dermis, deciduous dentin) shows a greater number of branches than the corresponding mature form, particularly that of calf. This may be due to cross-linking in mature collagen. The number of branches of calf dermis collagen is similar to that of gelatin, and the number of grafted-MMA branches of dentin powder shows a value similar that of soft tissue type-one collagen.

There have been some reports of graft copolymerization of methacrylates with hydrated collagen by use of ceric ammonium nitrate [42] and potassium persulfate [43] as an initiator. There is an increase in the percentage grafting of collagen with such initiators. The activation energy $\left(E_{a}\right)$ of graft copolymerization for acryl amide and methyl methacrylate onto cellulose by ceric ammonium nitrate is low (circa $3.4 \mathrm{kcal} / \mathrm{mol}$ ), being within a temperature range of $20{ }^{\circ} \mathrm{C}$ to $45{ }^{\circ} \mathrm{C}$ [42]. By contrast, the overall $\mathrm{E}_{\mathrm{a}}$ of aqueous polymerization of acryl amide by potassium persulfate/2-mercaptoethanol is circa $32.1 \mathrm{kcal} / \mathrm{mol}$ ) [43]. The $\mathrm{E}_{\mathrm{a}}$ of ceric ammonium nitrate is similar to that of tri- $n$-butylborane, whereas that of the potassium persulfate/2-mercaptoethanol redox system is 8-fold greater than that of tri-n-butylborane. As described in 3.2.1, the molecular weight of the heavy component of MMA-grafted silk fiber with the tri-n-butylborane reaction system is about 4-fold greater than that with the potassium persulfate reaction system [33]. This indicates that the tri- $n$-butylborane system may be applicable for enhancing the molecular weight of MMA-grafted branches. The characterization of copolymerization by the tri- $n$-butylborane reaction system probably promotes the adhesive strength of this resin system to tooth collagen due to the high percentage grafting with a large molecular weight, even if the MMA-grafted chains are considerably small. 
Table 5. Tri-n-butylborane-initiated graft copolymerization of methyl methacrylates with hydrated various collagens (A) and bovine dentin powder (B).

A

\begin{tabular}{lccc}
\hline & $\begin{array}{c}\text { Percent graft } \\
(\%)\end{array}$ & $\begin{array}{c}\text { Mol. wt. of grafted- } \\
\text { PMMA branch } \\
\times 10^{-5}\end{array}$ & $\begin{array}{c}\text { No. of grated-PMMA } \\
\text { branch (mole/g-collagen) } \\
\times 10^{6}\end{array}$ \\
\hline Cype one collagen & 48.8 & 7.6 & 0.6 \\
Calf dermis & 4 & 6.5 & 0.1 \\
Batur bovine dermis & 7 & 9.6 & 0.1 \\
Bovine achilles tendon & 12.6 & 7.5 & 0.2 \\
Bovine peridontal ligament & 8.9 & 10.5 & 0.1 \\
Bovine femoral bone & 15.2 & 10.9 & 0.1 \\
Dentin (human permanent teeth) & 4.3 & 6 & 0.1 \\
Dentin (human permanent teeth) & 13.5 & 9.3 & 0.2 \\
Dentin (human decidous teeth) & 10 & 6.8 & 0.2 \\
\hline B & & & No. of grafted-PMMA \\
\hline & & Mol. wt. of grafted- & branch (mole/g-collagen) \\
Bovine dentin powder & $(\%)$ & PMMA branch & $\times 10^{6}$ \\
\hline Dentin (mesh-size 200-325) & 0 & $\times 10^{-5}$ & - \\
Dentin(mesh-size 200-325) & 27.6 & - & 0.2 \\
Dentin (mesh-size 180-200) & 11.7 & 19.5 & 0.3 \\
Dentin (mesh-size 180-200) & 8.6 & 7 & 0.1 \\
\hline
\end{tabular}

Samples of A, $0.051-0.060 \mathrm{~g}$; samples of $\mathrm{B}$, each $0.200 \mathrm{~g}$ powder containing approximately $0.036 \mathrm{~g}$ collagen; The experimental condition is similar to that shown in Table 3. ${ }^{\mathrm{a}}$ boiled at $100{ }^{\circ} \mathrm{C}$ for $2 \mathrm{~h}$; ${ }^{\mathrm{b}}$ no water; ${ }^{\mathrm{c}}$ boiled at $70{ }^{\circ} \mathrm{C}$ for $3 \mathrm{~h}$.

To elucidate the good adaptation of tri- $n$-butylborane-initiated PMMA resins to the cavity prepared after caries treatments, Masuhara [3] previously reported the beneficial effect of the polymerization of MMA initiated by tri-n-butylborane on tooth structures. Results are shown in Figure 2.

These simple experimental results suggested that polymerization of MMA initiated by the TBB system may occur preferably at moist dentin surface with collagens because native collagen fibers contain water intrinsically and consequently, a good cavity adaptation between dentin and the resin may be obtained [3] (Figure 2B). Indeed, the good adhesive ability of TBB-system resins provided sufficient protection of pulp [4,5]. Note: Dentin collagen has a proportion of circa $20 \%$ of dentin, whereas enamel contains no collagen and other proteins are $<<1 \%$. Currently, in adhesive dentistry, tooth surfaces are treated by acids for a few seconds to enhance the adhesive strength of resin to tooth. Tooth enamel surfaces are decalcified by this etching treatment and most of etched hard-tissues are a well-known brushite (dicalcium phosphate dihydrate, $\mathrm{CaHPO}_{4} \quad 2 \mathrm{H}_{2} \mathrm{O}$ ) which is derived from hydroxyapatite of enamel structure. The formed brushite layer (porous layer with about $50 \mu \mathrm{m}$ width) works as an anchor site for adhesive materials, in addition to the marked increase of enamel surface area due to etching treatments. Since brushite has a better affinity to water than that of hydroxyapatite, TBB-initiated resins for enamel bonding systems with a coupling agent were more effective, compared with BPO/tert-amine' ones [3]. 
Figure 2. The distinct difference of polymerization behavior of methyl methacrylate (MMA) at the surface of water between (a) tri- $n$-butylborane (TBB) and (b) benzoyl peroxide (BPO)/tert-amine systems (retouched figure taken from the Ref. [3] with permission.) (A) and tooth structure and cavity (B). A given amount of MMA and water were added to sample tubes. The mixture solution was partitioned into the two phases of water and MMA; the upper phase, MMA and the lower phase, water. Next, to initiate polymerization, $\mathrm{TBB}$ and $\mathrm{BPO} /$ tert-amine initiators were added to sample tubes, respectively. a) TBB-initiated polymerization began at the surface of water. Resin forming occurred in water. b) BPO/tert-amine-initiated polymerization occurred in the central part of MMA solution and accelerated circumferentially. Also, no polymerization was influenced by water. Polymerization shrinkage occurred toward the center of the resin body in a tube.

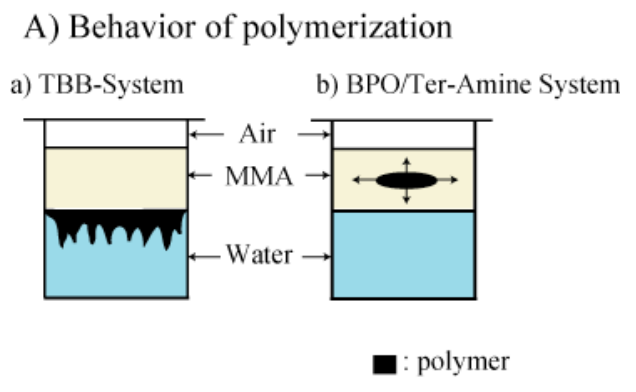

B) Tooth structure and cavity

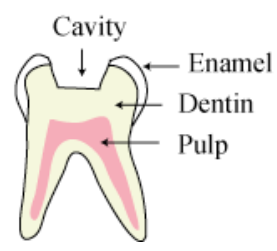

Ikemura et al. [44] recently wrote a review titled "Our development of dental adhesives". They reported as follows: Based on the general principle of adhesion that is "good wettability and good hardening", our research strategy has focused on the dual effects of radical polymerization initiators (to make good hardening) and adhesive monomers (to form good wettability) on adhesion.

Currently, selfcuring PMMA resins initiated by partly oxidized tri-n-butylborane have undoubtedly achieved success in delivering outstanding bonding performance [44]. Note: Partly oxidized tri- $n$-butylborane is used commercially, since tri- $n$-butylborane is unstable in air. Many researchers seek more stable polymerization initiators with active initiation like tri- $n$-butylborane.

\section{Polymerization with Low Surface-Energy Plastics}

Polyolefins and their copolymers are useful in the fabrication of many objects including automotive components, footwear, toys, and household appliances. Low surface-energy plastics such as polyolefins, i.e., polyethylene (PE) and polypropylene (PP), are known to have difficulty bonding together and to other surfaces using adhesive bonding technology; the inherent low surface-energy of polyolefins inhibits adhesion to most adhesive and coating formulations which tend to contain polar materials such 
as urethanes, acrylics, and epoxies. Low energy surfaces typically have surface-energy values of less than $45 \mathrm{~mJ} / \mathrm{m}^{2}$, more typically less than $40 \mathrm{~mJ} / \mathrm{m}^{2}$. To clarify the mechanism of tri- $n$-butylboraneinitiated polymerization of MMA, we previously investigated the graft polymerization of MMA onto PP, $\mathrm{PE}$ and cellulose acetate fiber under the following condition: backbone polymer, 0.05-0.06 g; MMA, $10 \mathrm{~mL}$; tri-n-butylborane, $0.15 \mathrm{~mL} ; 37^{\circ} \mathrm{C}$ and reaction time for $1 \mathrm{~h}$ in air [19]. Percent graft (\%) for PP, PE, cellulose acetate fiber, poly-L-Ala and poly-Gly in the absence of water was 720, 223, 44, 0 and 0 , respectively. PP and PE, particularly the former showed an excellent percent graft value, whereas poly-L-Ala and poly-Gly showed no percent graft. PP and PE were used as a model for poly-Ala and poly-Gly, respectively. These findings indicated that the behavior of the tri- $n$-butylborane-initiated polymerization with PP and poly-L-Ala shows a great difference in the absence of water. Radicals derived from tri-n-butylboranes may not abstract hydrogen from a poly-L-Ala surface in the absence of water (Figure 3). Recently, excellent adhesion to low surface-energy plastics such as PP, PE, poly(vinylidene difluoride), and poly(tetrafluoroethylene) has been obtained with acrylic polymerization initiated by trialkylboranes at room temperature and without need for surface pretreatments [45,46]. Okamura et al. [45] examined the graft copolymerization of ethyl acrylate and $n$-butyl acrylate onto surface of PP using a redox system composed of triethylborane $\left(\mathrm{Et}_{3} \mathrm{~B}\right)$ and molecular oxygen in air, indicating that the amounts of the grafted polymers increased by prolonging a period of soaking $\mathrm{PP}$ in a solution of $\mathrm{Et}_{3} \mathrm{~B}$ in $n$-hexane, a less polar solvent of which affinity with PP would be higher than that of tetrahydrofuran, a highly polar solvent. Also, Sonnenschein et al. [46] examined the graft polymerization of maleic anhydride (MAH) onto the compound 2,6,10,14-tetramethylpentadecane ("pristane" as a model for PP) with $\mathrm{Et}_{3} \mathrm{~B}$ in contact with air. MAH is a grafting monomer particularly useful in this experiment since it will not homopolymerize. They reported that the mechanism of adhesion is a consequence of a series of radical processes resulting from the initial oxidation of the trialkylborane followed by the production of alkoxy and alkyl radicals and also that alkoxy radicals may abstract hydrogen from an olefin surface [46].

Figure 3. A possible mechanism of $\mathrm{H}$-abstraction by alkoxy radical from a polypropylene surface. An H-abstraction from poly-L-Ala alpha-carbon possibly does not occur.

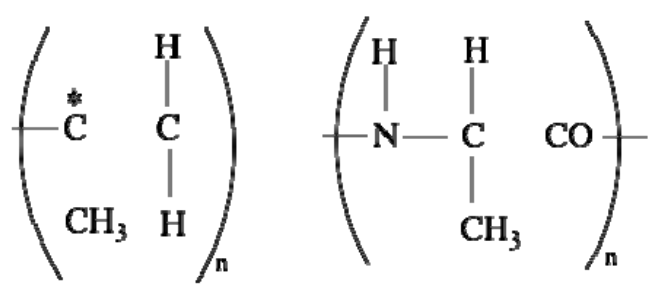

Polypropylcne-Radical Poly-L-Alaninc

The adhesive bonding systems with adherence to low surface-energy plastics using trialkylboranes, may be applicable for practical use without need of surface pretreatments such as flame treatments, plasma treatments, oxidation, sputter etching, corona discharge, or primer treatments with a high surface-energy materials.

Trialkylborane initiators and their amine complexes are hydrolytically and oxidatively unstable [23]. Sonnenschein et al. [47] recently reported that trialkylborane-amine complexes decompose in water very rapidly to trialkylboroxin, borate esters, and boric acid; these complexes can be stored in an 
aqueous solution of several water-miscible acrylate polymers; can be mixed with polymerizable monomers such as acrylates and are stable for long periods of time ( $>3$ months). These trialkylboraneamine complexes, colloidal initiators, may be useful in producing adhesives capable of adhering not only to low surface-energy plastics but also natural polymers such as collagens and silks.

On the other hand, the use of artificial liposomes (lipid bilayers) as a model for various biological membranes such as erythrocytes has become of interest, because the liposomes have proved to be useful in exploring the mechanism whereby drugs, detergents, and vinyl monomers act on the phospholipids bilayer [31,48]. We previously employed dipalmitoyl phosphatidylcholine (DPPC) liposomes in order to study the interaction of tri- $n$-butylborane with lipid bilayers. DPPC liposome was prepared as follows; An appropriate amount of DPPC was dissolved in chloroform and dried under vacuum. The dried DPPC film was dispersed in water by vortexing on a shaker at $45{ }^{\circ} \mathrm{C}$ for $2-3 \mathrm{~min}$ and then sonicated under a nitrogen atomosphere for $3-5 \mathrm{~min}$ at $45{ }^{\circ} \mathrm{C}$. The concentration of DPPC was circa $10 \%(\mathrm{w} / \mathrm{w})$. An appropriate concentration of TBBO (partly oxidized tri- $n$-butylborane) was added to DPPC liposomes. After $10 \mathrm{~min}$, the phase transition temperature $(\mathrm{Tm})$, enthalpy $(\Delta \mathrm{H})$ and [Height]/[Half-Height Width] of the peak for an aliquot of sample $(20 \mu \mathrm{L})$ with tri-n-butylboranetreated DPPC liposome were determined using differential scanning calorimetry (DSC). TBBO concentration-dependently shifted $\mathrm{Tm}$ to a lower temperature with decreasing $\Delta \mathrm{H}$ and increasing [Height]/[Half-Height Width]. The Tm of main peak for DPPC liposome (control) was $41^{\circ} \mathrm{C}$, whereas that for TBBO-treated liposome (DPPC: $\mathrm{TBBO}=9: 1, \mathrm{w} / \mathrm{w}$ ) was approximately $35{ }^{\circ} \mathrm{C}$. The $\Delta \mathrm{H}$ for control was $36.4 \mathrm{~kJ} \mathrm{~mol}^{-1}$, whereas that for the TBBO-treated liposome was approximately a half of control (unpublished data). It was assumed from this that tri-n-butylborane is preferably incorporated into lipid bilayers. This finding suggested that tri-n-butylborane may be applicable for developing the colloidal initiator [47] and capsule liposome systems [49] Currently, borane derivatives have been used to develop an attractive new procedure for the reduction of radicals with alcohol and water.

\section{Conclusions}

The characterization of tri- $n$-butylborane-initiated polymerization and copolymerization of MMA in the presence of water is not similar to that of tri-n-butylborane-initiated polymerization in the usual organic solvents. The catalytic effect of amino acids on tri-n-butylborane-initiated polymerization of MMA in the presence of water is correlated with their ionization potential (IP), suggesting that tri- $n$-butylborane/water-mediated radicals are ionic. A significant exponential relationship between the number of grafted-PMMA branches of polypeptides and the $\Delta \varepsilon$ HOMO of the corresponding amino acids is observed. Amino acids with a high $\Delta \varepsilon$ HOMO show a large number of grafted-PMMA branches. The tri-n-butylborane/water complex-mediated graft copolymerization of MMA with collagen and gelatin is characterized by an increase in both the percentage grafting and the average molecular weight of grafted-PMMA branches, resulting in a small number of grafted-PMMA branches (0.1). On the other hand, silk fibroin having a molecular weight of the grafted-PMMA branch approximately 10-fold smaller than that of collagen, shows the highest number of branches among the proteins tested, but does not exceed 2. Excellent percent grafts for low surface-energy plastics such as polypropylene and polyethylene with tri-n-butylborane are observed in the absence of water. 


\section{Acknowledgements}

The authors dedicate this mini-review to the late emeritus E. Masuhara of Tokyo Medical and Dental University. This work was compiled on the basis of published materials and current knowledge. We thank Y. Imai and K. Kojima, who worked previously with us in the research laboratory under Masuhara, for kind and helpful coaching. Also, we thank M. Ishihara of Meikai University for helpful discussions.

\section{References}

1. Lao, K.P.; Joseph, K.T.; Nayudamma, Y. Graft polymerization of vinyl monomers onto collagen by cerium (IV) ions. Leder 1968, 19, 77-83.

2. Brauer, G.M.; Termini, D.J. Grafting of acrylates and vinyl chains onto collagen with ceric initiator. J. Appl. Polym. Sci. 1973, 17, 2557-2568.

3. Masuhara, E. On the chemistry of a new adhesive plastic filling material (in German). Dtsch Zahnarztl Z. 1969, 24, 620-628.

4. Fischer, C.H.; Strassburg, M.; Knolle, G. Tests with a new synthetic filling material over a period of three years (Palakav). Int. Dent. J. 1970, 20, 679-689.

5. Sanjo, D. Clinical studies on a cold-curing dental resin with a tri- $n$-butylborane catalyst. J. Dent. Res. 1971, 50, 60-65.

6. Kadoma, Y.; Imai, Y. Effect of ferric salts on polymerization of MMA by TBBO in the presence of a collagen sheet. A model to study the mechanism of adhesion of MMA resin to dentin (in Japanese). J. Jpn. Dent. Mater. 1988, 7, 817-823.

7. Nakabayashi, N.; Watanabe, A.; Gendusa, N.J. Dentin adhesion of "modified "4-META-TBB resin: Function of HEMA. Dent. Mater. 1992, 8, 259-264.

8. Kojima, K.; Iguchi, S.; Kojima, Y.; Yoshikuni, M. Grafting of methyl methacrylate onto collagen initiated by tributylborane. J. Appl. Polym. Sci. 1982, 28, 87-95.

9. Kojima, K.; Yoshikuni, M.; Suzuki, T. Tributylborane-initiated grafting of methyl methacrylate onto chitin. J. Appl. Polym. Sci. 1979, 24, 1587-1593.

10. Kojima, K.; Iwabuchi, S.; Murakami, K.; Kojima, K.; Ichikawa, F. The grafting of methyl methacrylate onto cotton by tri-n-butylborane. J. Appl. Polym. Sci. 1972, 16, 1139-1148.

11. Tsukada, M.; Yamamoto, T.; Nakabayashi, N.; Ishikawa, H.; Freddi, G. Grafting of methyl methacrylate onto silk fibers initiated by tri-n-butylborane. J. Appl. Polym. Sci. 1991, 43, 2115-2121.

12. Kojima, K.; Iwabuchi, S.; Tarumi, N.; Masuhara, E. Grafting of methyl methacrylate and its derivatives onto blood. J. Polym. Sci A 1971, 9, 3213-3224.

13. Kojima, K.; Iwabuchi, S.; Kojima, K. The trialkylborane-initiated graft copolymerization of methyl methacrylate onto hemoglobin. Bull. Chem. Soc. Jp. 1971, 44, 1891-1895.

14. Mirvis, S.B. Air oxidation of trialkylboranes. J. Am. Chem. Soc. 1961, 83, 3051-3056.

15. Welch, F.J. Polymerization of methyl methacrylate by triethylboron-oxygen mixtures. J. Polym. Sci. 1962, 61, 243-252.

16. Mirviss, S.B. Mechanism of the oxidation of trialkylboranes. J. Org. Chem. 1967, 32, 1713-1717. 
17. Renaud, P.; Beauseigneur, A.; Brecht-Forster, A.; Becattini, B.; Darmency, V.; Kandhasamy, S.; Montermini, F.; Ollivier, C.; Panchaud, P.; Pozzi, D.; Scanlan, E.M.; Schaffner, A.-P.; Weber, V. Boron: A key element in radical reactions. Pure Appl. Chem. 2007, 79, 223-233.

18. Fujisawa, S. The mechanism of adhesive bonding between dental self-curing resins and human dentin with tri- $n$-butylborane catalyst (I) (in Japanese). J. Jpn. Soc. Dent. App. Mater. 1968, 9, 167-173.

19. Fujisawa, S. The mechanism of adhesive bonding between dental self-curing resins and human dentin with tri-n-butylborane catalyst (II) (in Japanese). J. Jpn. Soc. Dent. App. Mater. 1969, 10, 47-51.

20. Fujisawa, S. The mechanism of adhesive bonding between dental self-curing resins and human dentin with tri-n-butylborane catalyst (III) (in Japanese). J. Jpn. Soc. Dent. App. Mater. 1970, 11, 197-201.

21. Kojima, K.; Iwata, Y.; Nagayama, M.; Iwabuchi, S. Polymerization of methyl methacrylate by trialkylborane-pyridine system. J. Polym. Sci. B 1970, 8, 541-547.

22. Kojima, K.; Umeda, M. Polymerization of methyl methacrylate initiated by tributylborane-metal acetylacetonate system (in Japanese). Nippon Kagaku Kaishi 1975, 12, 2221-2224.

23. Fujisawa, S.; Imai, Y.; Masuhara, E. Studies of dental self-curing resin (XI). Characterization of the various complexes of tri-n-butylborane as an initiator (in Japanese). Rep. Inst. Med. Dent. Eng. 1969, 3, 64-71.

24. Kojima, K.; Iwabuchi, S.; Moriya, Y.; Yoshikuni, M. Polymerization of methyl methacrylate by tri-n-butylborane in the presence of amino acid esters. Polymer 1975, 16, 601-604.

25. Brindley, P.B.; Pearson, R.G. Free-radical polymerization of methyl methacrylate in the presence of trialkylboranes. J. Polym. Sci. B Polym. Lett. 1968, 6, 831-835.

26. Nelson, D.J.; Cooper, P.J. An experimental and theoretical investigation of the influence of alkene HOMO energy level upon the hydroboration reaction. Additional evidence supporting an early transition state which has retention of alkene character. Tetrahedron Lett. 1986, 27, 4693-4696.

27. Wang, X.; Li, Y.; Wu, Y.-D.; Paddon-Row, M.N.; Rondan, N.G.; Houk, K.N. Ab initio transition structures for hydroborations of alkenes, allenes, and alkynes by borane, diborane, methylborane, methylfluoroborane, and dimethylborane. J. Org. Chem. 1990, 55, 2601-2609.

28. Spiegel, D.A.; Wiberg, K.B.; Schacherer, L.N.; Medeiros, M.R.; Wood, J.L. Deoxygenation of alcohols employing water as the hydrogen atom source. Am. Chem. Soc. 2005, 127, 12513-12515.

29. Fukazawa, Y.; Fujii, H.; Kamimoto, Y. Energy of amino acids by quantum chemical calculation (in Japanese). Kenkyu Hokoku Kanagawa-ken Sangyo Gijutsu Senta 2007, 13, 15-19.

30. Koopmans, T. The distribution of wave function and characteristic value among the individual electrons of an atom. Physical 1933, 1, 104-113.

31. Fujisawa, S.; Kadoma, Y.; Ishihara, M.; Atsumi, T.; Yokoe, I. Dipalmitoylphosphatidylcholine (DPPC) and DPPC/cholesterol liposomes as predictors of the cytotoxicity of bis-GMA related compounds. J. Lipos. R 2004, 14, 39-49.

32. Cao, Y.; Wang, B. Biodegradation of silk biomaterials. Int. J. Mol. Sci. 2009, 10, 1514-1524.

33. Tsukada, M.; Yamamoto, T.; Nakabayashi, N.; Ishikawa, H.; Freddi, G. Molecular weight distribution of the methyl methacrylate (MMA) polymer separated from the MMA-grafted silk fiber. J. Appl. Polym. Sci. 1992, 44, 2197-2202. 
34. Court, A. Relationships between collagen and gelatin. In The Science and Technology of Gelatin; Ward, A.G., Court, A., Eds.; Academic Press: New York, NY, USA, 1970; pp. 137-177.

35. Ramshaw, J.A.; Shah, N.K.; Brodsky, B. Gly-X-Y tripeptide frequencies in collagen: A context for host-guest triple-helical peptides. J. Struct. Biol. 1998, 122, 86-91.

36. Nisbet, A.D.; Saundry, R.H.; Moir, A.J.G.; Fothergill, L.A.; Fothergill, J.E. The complete amino-acid sequence of hen ovalbumin. Eur. J. Biochem. 1981, 115, 335-345.

37. Handa, A.; Hayashi, K.; Shidara, H.; Kuroda, N. Correlation of the protein structure and gelling properties in dried egg white products. J. Agric. Food Chem. 2001, 49, 3957-3964.

38. Corfield, M.C.; Robson, A. The amino acid composition of wool. Biochem. J. 1955, 59, 62-68.

39. O'Neil, G.A.; Wisnudel, M.B.; Torkelson, J.M.A. Critical experimental examination of the gel effect in free radical polymerization: Do entanglements cause autoacceleration? Macromolecules 1996, 29, 7477-7490.

40. Pietrucha, K.; Pëkala, W.; Kroh, J. Radiation induced graft copolymerization of methyl methacrylate onto chrome-tanned pig skins. Rad. Phys. Chem. 1981, 18, 489-501.

41. Zahn, H.; Scehade, W.; Ziegler, K. Fractionation of the chymotryptic precipitate of bombyx mori silk fibroin. Biochem. J. 1967, 104, 1019-1025.

42. Gupta, K.C.; Khandekar, K. Acrylamide-methyl methacrylate graft copolymerization onto cellulose using ceric ammonium nitrate. J. Macromol. Sci. A 2003, 40, 155-179.

43. Husain, M.M.; Misra, S.N.; Gupta, A.A. Studies on aqueous polymerization of acrylamide, 2. Potassium persulfate/2-mercaptoethanol redox system. Makromol. Chem. 1976, 77, 2919-2926.

44. Ikemura, K.; Endo, T. A review of our development of dental adhesives-Effects of radical polymerization initiators and adhesive monomers on adhesion. Den. Mater. J. 2010, 29,109-121.

45. Okamura, H.; Sudo, A.; Endo, T. Generation of radical species on polypropylene by alkylboraneoxygen system and its application of graft polymerization. J. Polym. Sci. A 2009, 47, 6163-6167.

46. Sonnenschein, M.F.; Webb, S.P.; Kastl, P.E.; Arriola, D.J.; Wendt, B.L.; Harrington, D.R. Mechanism of trialkylborane promoted adhesion to low surface energy plastics. Macromolecules 2004, 37, 7974-7978.

47. Sonnenschein, M.F.; Redwine, O.D.; Wendt, B.L.; Kastl, P.E. Colloidal encapsulation of hydrolytically and oxidatively unstable organoborane catalysts and their use in waterborne acrylic polymerization. Langmuir 2009, 25, 12488-12494.

48. Fujisawa, S.; Kadoma, K. Hemolytic activity of a dental adhesive monomer and its interaction with dipalmitoyl phosphatidylcholine liposomes. NMR and DSC measurement. J. Thermal Anal. 1998, 51, 151-160.

49. Städler, B.; Price, A.D.; Rona Chandrawati, R.; Hosta-Rigau, L.; Alexander, N. Zelikin, A.N.; Caruso, F. Polymer hydrogel capsules: En route toward synthetic cellular systems. Nanoscale 2009, 1, 68-73.

(C) 2010 by the authors; licensee MDPI, Basel, Switzerland. This article is an open access article distributed under the terms and conditions of the Creative Commons Attribution license (http://creativecommons.org/licenses/by/3.0/). 